\title{
Demographic history and interspecific hybridization of four Shorea species (Dipterocarpaceae) from Peninsular Malaysia inferred from nucleotide polymorphism in nuclear gene regions
}

\begin{abstract}
Shorea acuminata Dyer, Shorea curtisii Dyer ex King, Shorea leprosula Miq., and Shorea parvifolia Dyer are dominant tree species in the tropical rainforest of Peninsular Malaysia, which experienced several climatic changes during Pleistocene. To investigate the current population structure and demographic history of these species, we analyzed levels and patterns of nucleotide polymorphism of the nuclear gene region PgiC. We also used sequence data of the GapC gene region obtained in our previous study. Negative Tajima's D values observed in both investigated gene regions for S. curtisii, S. leprosula, and S. parvifolia implied that all three species have experienced population expansion events. Little to moderate levels of population differentiation in S. acuminata and S. curtisii suggested recent divergence of the investigated populations after postglacial colonization of the Peninsular Malaysia. In addition, some haplotypes were similar or identical to haplotypes of the other species. The existence of such haplotypes could be partially explained by interspecific hybridization. Indeed, we found some putative hybrid individuals. Interspecific hybridization among closely related species might have contributed to the polymorphism of the investigated species.
\end{abstract}

Keyword: Dipterocarpaceae, Peninsular Malaysia, nucleotide, polymorphism 